\title{
Common Bean Fe Biofortification Using Model Species' Lessons
}

\author{
Raul A. Sperotto ${ }^{1 *}$ and Felipe K. Ricachenevsky ${ }^{2,3 *}$ \\ ${ }^{1}$ Biological Sciences and Health Center, Graduate Program in Biotechnology, University of Taquari Valley - UNIVATES, \\ Lajeado, Brazil, ${ }^{2}$ Graduate Program in Agrobiology, Biology Department, Federal University of Santa Maria, Santa Maria, \\ Brazil, ${ }^{3}$ Graduate Program in Cell and Molecular Biology, Federal University of Rio Grande do Sul, Porto Alegre, Brazil
}

Keywords: anti-nutrient, bean, biofortification, iron, model species, Phaseolus vulgaris, transgenic strategies

\section{OPEN ACCESS}

Edited by:

Sebastien Thomine,

Centre National de la Recherche Scientifique (CNRS), France

Reviewed by:

Louis Grillet,

Academia Sinica, Taiwan

*Correspondence:

Raul A. Sperotto

rasperotto@univates.br

Felipe K. Ricachenevsky

felipecruzalta@yahoo.com.br

Specialty section:

This article was submitted to

Plant Nutrition,

a section of the journal

Frontiers in Plant Science

Received: 23 October 2017 Accepted: 12 December 2017 Published: 22 December 2017

Citation:

Sperotto RA and Ricachenevsky FK (2017) Common Bean Fe Biofortification Using Model Species' Lessons. Front. Plant Sci. 8:2187. doi: 10.3389/fp/s.2017.02187
Common bean (Phaseolus vulgaris L.) is the most widely grown grain legume for direct human consumption and is highly preferred in many parts of Africa and Latin America, as well as in southern Europe (Broughton et al., 2003; Blair and Izquierdo, 2012). It is an important source of nutrients for more than 300 million people, representing $65 \%$ of total protein consumed, $32 \%$ of energy, and a major source of micronutrients e.g., iron ( $\mathrm{Fe})$, zinc, thiamin, and folic acid (Welch et al., 2000; Broughton et al., 2003; Blair et al., 2010a; Petry et al., 2015). It is known as the "poor men's meat," due to its high protein, minerals, and vitamins content (Blair, 2013). Fe is an essential micronutrient for almost all living organisms (Bashir et al., 2013), and Fe deficiency is the most common micronutrient deficiency worldwide, disproportionately affecting the poorest and most vulnerable populations in resource-limited settings, leading to Fe deficiency anemia (IDA; Stevens et al., 2013; Finkelstein et al., 2017). IDA is difficult to address through Fe supplementation or processed foods; therefore, several attempts are being made to enhance Fe accumulation into staples such as rice, maize, wheat, and legumes (Blair and Izquierdo, 2012) using biofortification, which is the process of breeding or genetic engineering to improve nutrient content in a crop (Blair, 2013). Biofortification is considered a sustainable and cost effective strategy to address malnutrition in developing countries because it targets staple foods that are consumed daily (Dwivedi et al., 2012).

Nutritional quality in common beans has been found to be higher than in cereals, with large amounts of minerals and vitamins accumulated in the seeds (Broughton et al., 2003). Common bean is estimated to have 4-10 times the amount of Fe, and 2-3 times the amount of $\mathrm{Zn}$ compared to rice (Pfeiffer and McClafferty, 2007). Also, these minerals and vitamins are generally retained after harvest and processing, while in polished cereal grains the Fe-rich tissues (embryo and aleurone layer) are lost (Wang et al., 2003). Although the average Fe concentration in beans is high, many people still suffer from IDA due to an insufficient level of bioavailable $\mathrm{Fe}$ in a monotonous cereal/bean-based diet without meat (Bouis, 2007). For Fe biofortification purposes, the use of common bean is advantageous because the baseline grain Fe content is high at 55 ppm and variability for the trait is great (Petry et al., 2015), ranging up to $110 \mathrm{ppm}$, allowing initial biofortification attempts to start from already high Fe levels (Blair et al., 2012; Blair, 2013). Another advantage of using common beans in biofortification programs is that seeds are consumed whole after boiling. Therefore, all major components of the common bean seed could be targets of biofortification: seed coat, cotyledons, and embryo (Blair et al., 2013).

The target Fe level of HarvestPlus, an international research program supporting the research and development of biofortified crops, is $94 \mathrm{ppm}$ in whole bean seeds (Blair and Izquierdo, 2012; Petry et al., 2015). According to Vasconcelos et al. (2017), in order to achieve $30 \%$ of the estimated average daily dietary requirement for Fe on a dry weight (DW) basis, the recommended Fe levels in whole beans should be $107 \mathrm{ppm}$. The target level was quickly reached, and in some countries plant breeders have already developed and released new $P$. vulgaris bean varieties with Fe concentrations of about 100 ppm (Petry et al., 2015). These varieties show good micronutrient retention after processing, and equal or increased agronomic yield (Bouis and Welch, 2010). However, successful 
bean Fe biofortification might be constrained due to the reported low Fe bioavailability (Ariza-Nieto et al., 2007) associated with high concentrations of Fe absorption inhibitors, also called antinutrients, such as polyphenols and phytate (Beninger et al., 2005; Petry et al., 2014). Here we propose multiple, complementary approaches to increase $\mathrm{Fe}$ concentration and bioavailability in common bean, based on the current knowledge on model species. These approaches are summarized in Figure 1.

\section{DECREASING ANTI-NUTRIENT CONCENTRATION AND CO-LOCALIZATION WITH FE IN SEEDS}

Short-term human isotope studies indicate that phytate is the major Fe absorption inhibitor in beans, with polyphenols playing a minor role (Petry et al., 2012, 2014). Phytate increases with the Fe concentration in beans, and both are mainly found in the cotyledons. It should be possible to simultaneously breed for high Fe and low phytate since most phytate-related QTLs are independent of Fe concentration QTLs (Blair et al., 2012, 2013). Two main strategies for phytate reduction in seeds have been attempted: disruption of its biosynthetic pathway with knockout/knockdown of inositol pentakisphosphate 2-kinase (IPK1) in Arabidopsis and rice showing decreased phytate in seeds and normal yield (Stevenson-Paulik et al., 2005; Ali et al., 2013), but with possible defects in Pi homeostasis (Kuo et al., 2014); and mutations on phytate vacuolar transporters expressed in seeds, which reduced phytate concentration in other species (Shi et al., 2007; Nagy et al., 2009; Xu et al., 2009). In common bean, disruption of the orthologous transporter PvMRP6 resulted in 90\% less phytate in seeds and normal

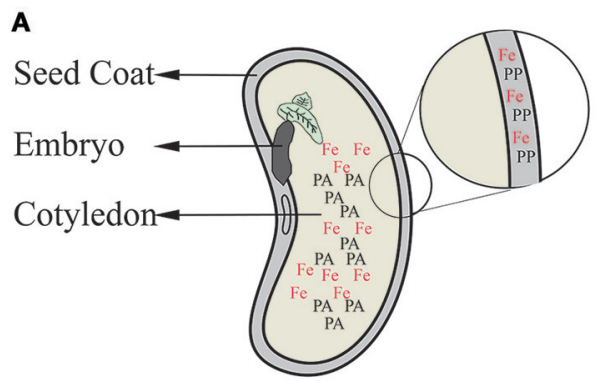

1.

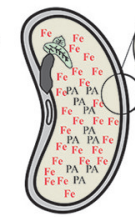

3.

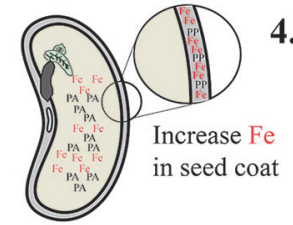

2.

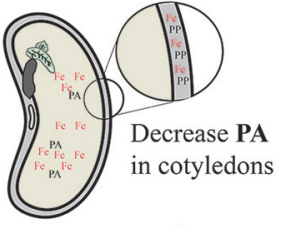

4.

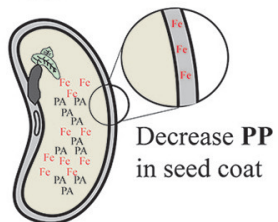

B

Table 1. Possible candidate genes for genetic engineering in common bean (P. vulgaris).

\begin{tabular}{lll}
\hline Locus in P. vulgaris & Description & Alteration \\
\hline Phvul.009G060100 & Inositol-Pentakisphosphate 2-Kinase (IPK) & Loss-of-function \\
Phvul.009G060100 & Inositol-Pentakisphosphate 2-Kinase (IPK) & Loss-of-function \\
Phvul.001G012200 & Inositol-Pentakisphosphate 2-Kinase (IPK) & Loss-of-function \\
Phvul.002G322900 & Vacuolar Iron Transporter (VIT) & Loss-of-function \\
Phvul.002G322800 & Vacuolar Iron Transporter (VIT) & Loss-of-function \\
Phvul.001G245700 & Ferritin & Seed-specific expression \\
Phvul.008G221200 & Ferritin & Seed-specific expression \\
Phvul.008G258100 & Ferritin & Seed-specific expression \\
Phvul.008G093700 & Ferritin & Seed-specific expression \\
Phvul.010G065600 & Ferritin & Seed-specific expression \\
Phvul.001G225000 & Nicotianamine Synthase (NAS) & Over-expression \\
Phvul.006G117300 & Nicotianamine Synthase (NAS) & Over-expression \\
Phvul.005G052500 & Nicotianamine Synthase (NAS) & Over-expression \\
Phvul.001G126400 & bHLH Subgroup Ib transcription factor & Over-expression \\
Phvul.004G156022 & BRUTUS/HRZ-Like & Loss-of-function/Knockdown \\
Phvul.003G194400 & BRUTUS/HRZ-Like & Loss-of-function/Knockdown \\
Phvul.002G317800 & BRUTUS/HRZ-Like & Loss-of-function/Knockdown \\
\hline
\end{tabular}

FIGURE 1 | Summary of proposed strategies to increase bioavailable Fe delivery in common bean (Phaseolus vulgaris) seeds. Different strategies might be used as complementary, non-excludent approaches for bean biofortification. (A) Schematic representation of common bean seed and its main parts: seed coat, embryo and cotyledons. In cotyledons, iron (Fe) is shown with phytate (PA), whereas in the seed coat (detail), Fe is shown with polyphenols (PP). Each one act as an Fe absorption inhibitor in the human gut, with PA being likely a stronger anti-nutrient than PP. (1) Strategy aiming at increasing Fe concentration in the cotyledons to overcome PA anti-nutrient properties. (2) Strategy aiming at decreasing PA concentration in the cotyledons, making Fe in this tissue more bioavailable. (3) Strategy aiming at increasing Fe concentration in the seed coat to overcome PP anti-nutrient properties. (4) Strategy aiming at decreasing PP concentration in the seed coat, making Fe in this tissue more bioavailable. (B) Proposed candidate genes for genetic engineering in common bean, based on previous studies in model species. These genes are orthologous to genes found in Arabidopsis thaliana based on BLAST searches, except for Phvul.001G012200, which is the best hit using a soybean (Glycine max) IPK gene as query (Yuan et al., 2012). For each candidate gene, the type of manipulation is indicated. 
agronomic performance (Panzeri et al., 2011; Campion et al., 2013). However, seeds were hard to cook and induced digestive problems in human subjects (Petry et al., 2016). Thus, further research is necessary to improve Fe bioavailability by decreasing phytate while maintaining agronomic performance and consumer preferences.

Biofortification in beans can target all seed tissues: the thick seed coat, two large cotyledons and a well-developed embryo (Blair et al., 2013), which comprise $7-10,85$, and $2-3 \%$ of seed weight, respectively (Ariza-Nieto et al., 2007). Remarkably, segregating populations derived from crosses between wild and cultivated parents showed that QTLs for Fe accumulation in each tissue segregate separately, and the $\mathrm{Fe}$ range and maximum amount observed in seed coat is higher than in cotyledons (Blair et al., 2013). Seed coat can contribute with as much as $26 \%$ of the total seed $\mathrm{Fe}$, and polyphenols, not phytate, are the main anti-nutrients in the tissue (ArizaNieto et al., 2007). Thus, exploring seed coat biofortification is promising, as little is known about which specific polyphenol molecules reduce Fe bioavailability and how reduction in their concentration might affect plant and seed physiology (Petry et al., 2015).

\section{FURTHER INCREASING FE ACCUMULATION IN BEANS}

Genetic engineering beans to accumulate higher $\mathrm{Fe}$ concentrations in seeds can benefit from work on model plants. Vacuolar Iron Transporter (VIT) family members are likely candidates, since they are involved in seed Fe localization and/or concentration in Arabidopsis and rice (Kim et al., 2006; Zhang et al., 2012). AtVIT1 localizes Fe to the provasculature, and changes in provasculature density have been proposed as a means to increase $\mathrm{Fe}$ content in seeds (Roschzttardtz et al., 2017). In rice, OsVIT1 and OsVIT2 are involved in flag leaf Fe pool regulation, and might also have a role in seed Fe localization (Zhang et al., 2012). Recent work showed that endosperm-specific overexpression of TaVIT2 increased $\mathrm{Fe}$ concentration in wheat endosperm (Connorton et al., 2017), indicating that VIT genes can increase tissue Fe sink strength.

In rice, overexpression of NICOTIANAMINE SYNTHASE (NAS) genes was shown to substantially increase $\mathrm{Fe}$ concentration in the endosperm, presumably increasing $\mathrm{Fe}$ translocation through the phloem (Johnson et al., 2011). In addition, OsNAS1 over-expression in rice plants enhance human Fe bioavailability from the high nicotianamine (NA) grains (Zheng et al., 2010). NA role in Fe long-distance transport is likely to be conserved in land plants (Schuler and Bauer, 2011), and therefore a similar approach could be applied to common bean. Wirth et al. (2009) overexpressed bean Ferritin, Arabidopsis Nicotianamine synthase, and Aspergillus fumigatus Phytase genes in rice plants, and detected 6.3fold increase in $\mathrm{Fe}$ concentration on the polished seeds. Aluru et al. (2011) used a lpa maize mutant to overexpress soybean Ferritin gene, and found 2.7-fold increase in seed
Fe concentration. Similar approaches could be certainly used in common bean plants in order to concomitantly decrease phytate levels and increase $\mathrm{Fe}$ accumulation and availability.

Another approach would be to explore genes that regulate $\mathrm{Fe}$ concentration. Over-expression of AtbHLH039 results in constitutive $\mathrm{Fe}$ deficiency response and increased $\mathrm{Fe}$ levels in leaves and seeds (Naranjo-Arcos et al., 2017). Interestingly, the bean genome has only one gene similar to all four subgroup Ib from Arabidopsis, which are known to be involved in Fe deficiency response (Brumbarova et al., 2015). Work in Arabidopsis and rice has shown that the negative regulators of Fe deficiency response BRUTUS/HRZ-like proteins could lead to increased Fe concentration in seeds of knockout/knockdown plants (Kobayashi et al., 2013; Hindt et al., 2017). Three BRUTUS/HRZ-like genes are found in the bean genome. Although promising, manipulation of regulatory proteins should be performed with caution, since plants might display undesired phenotypic changes besides increased Fe in seeds.

Common bean genetic transformation protocols are lengthy and of low reproducibility, while in vitro plant regeneration is especially difficult (Veltcheva et al., 2005; Rech et al., 2008). The Agrobacterium rhizogenes system allow for bean root transformation and could be used for characterization and selection of candidate genes for stable transformation (EstradaNavarrete et al., 2007). Another solution is CRISPR-Cas9mediated genome editing, which does not necessarily require transformation (Malnoy et al., 2016; Wolt et al., 2016) and could circumvent the problem in the near future. However, using this method, it would be easier to knockout a specific gene than overexpress it.

\section{EXPLORING BEAN NATURAL VARIATION AND WILD RELATIVES}

The wide genetic Fe variability of beans has enabled plant breeders to develop varieties with twice Fe compared to normal beans (Blair et al., 2010b). Common bean is native to Latin America, and is one of the five cultivated species of the Phaseolus genus. It has two main genetic pools: Andean (large seeds) and Mesoamerican (small seeds). Andean and intergene-pool hybrids have higher Fe concentrations compared to Measoamerican ones, although the range of variation is similar (Blair, 2013). Large germplasm collection screenings for high Fe genotypes conducted in local and wild varieties of $P$. vulgaris have reported up to $110 \mathrm{ppm} \mathrm{Fe}$. However, early analyses on closely related species such as $P$. coccineus and $P$. dumosus have found up to $127 \mathrm{ppm} \mathrm{Fe}$, indicating that wild relatives might be useful (Blair et al., 2013). Even considering that high Fe wild genetic material showed poor agronomical performance (and introgression might not be straightforward in interspecific crosses), further screening of wild genotypes is promising. Moreover, wild beans accumulate more $\mathrm{Fe}$ in seed coats and less in cotyledons compared to domesticated genotypes, indicating that they can contribute differently for tissue-specific biofortification (Blair et al., 2013). 
QTL studies show that multiple genes regulate seed Fe levels (Blair and Izquierdo, 2012; Blair et al., 2013). Interestingly, Fe concentration inheritance seems to be associated with $\mathrm{Zn}$ concentration, as found in other crops, indicating that similar genes are involved in micronutrient loading in seeds and that breeding for both minerals simultaneously is feasible (Blair et al., 2013). Based on QTL localization, $\mathrm{Fe}$ and $\mathrm{Zn}$ concentration might be associated with the seed storage protein Phaseolin, whereas the Fe storage protein Ferritin was also associated with a QTL (Blair et al., 2009). Indeed, engineering for increased Ferritin expression in endosperm of Poaceae species have been a relatively successful strategy (Sperotto et al., 2012), and thus Ferritin-associated QTLs are interesting candidates. Fe-chelate reductase, which is important for Fe uptake in roots, has also been suggested as a possible candidate gene (Blair et al., 2013).

\section{WHERE TO FOCUS NEXT?}

Biofortification for any crop will benefit from multiple approaches, which can improve one another to achieve target Fe seed levels. For common bean, bioavailability tests are key due to the high level of anti-nutrients. The Caco-2 cell in vitro model has been widely used, with better results than previous in vivo absorption models (Ariza-Nieto et al., 2007; Blair et al., 2013; Petry et al., 2016). Recently, a new model using poultry (Gallus gallus) combined with Caco-2 cells showed that they can

\section{REFERENCES}

Ali, S., Paul, S., Gayen, D., Sarkar, S. N., Datta, K., and Datta, S. K. (2013). Development of low phytate rice by RNAi mediated seed-specific silencing of inositol 1,3,4,5,6-pentakisphosphate 2-kinase gene (IPK1). PLoS ONE 8:e68161. doi: 10.1371 /journal.pone.0068161

Aluru, M. R., Rodermel, S. R., and Reddy, M. B. (2011). Genetic modification of low phytic acid 1-1 maize to enhance iron content and bioavailability. J. Agric. Food Chem. 59, 12954-12962. doi: 10.1021/jf203485a

Ariza-Nieto, M., Blair, M. W., Welch, R. M., and Glahn, R. P. (2007). Screening of bioavailability patterns in eight bean (Phaseolus vulgaris L.) genotypes using the Caco-2 cell in vitro model. J. Agric. Food Chem. 55, 7950-7956. doi: 10.1021/jf070023y

Bashir, K., Nozoye, T., Ishimaru, Y., Nakanishi, H., and Nishizawa, N. K. (2013). Exploiting new tools for iron bio-fortification of rice. Biotechnol. Adv. 31, 1624-1633. doi: 10.1016/j.biotechadv.2013.08.012

Beninger, C. W., Gu, L. W., Prior, R. L., Junk, D. C., Vandenberg, A., and Bett, K. E. (2005). Changes in polyphenols of the seed coat during the afterdarkening process in pinto beans (Phaseolus vulgaris L.). J. Agric. Food Chem. 53, 7777-7782. doi: 10.1021/jf0500511

Blair, M. W. (2013). Mineral biofortification strategies for food staples: the example of common bean. J. Agric. Food Chem. 61, 8287-8294. doi: 10.1021/jf400774y

Blair, M. W., Astudillo, C., Grusak, M., Graham, R., and Beebe, S. (2009). Inheritance of seed iron and zinc content in common bean (Phaseolus vulgaris L.). Mol. Breed. 23, 197-207. doi: 10.1007/s11032-008-9225-z

Blair, M. W., Gonzales, L. F., Kimani, P. M., and Butare, L. (2010a). Genetic diversity, inter-gene pool introgression and nutritional quality of common beans (Phaseolus vulgaris L.) from central Africa. Theor. Appl. Genet. 121, 237-248. doi: 10.1007/s00122-010-1305-x

Blair, M. W., Herrera, A. L., Sandoval, T. A., Caldas, G. V., Filleppi, M., and Sparvoli, F. (2012). Inheritance of seed phytate and phosphorus levels in be used as a robust, cost-effective two-step system to evaluate Fe bioavailability, which should be mandatory to generate as well as to monitor biofortified crop seeds after their release (Tako et al., 2016).

Another focus should be to independently increase $\mathrm{Fe}$ in cotyledons and in seed coat, and understand the physiological roles of phytate/polyphenols and the effects of their reduction on seed viability and seedling establishment. Fe in cotyledons accumulates at the vascular bundles (Cvitanich et al., 2010), similar to Arabidopsis where it depends on Vacuolar Iron Transporter (VIT1; Kim et al., 2006). Phytate is also likely to accumulate in vacuoles, based on the activity of MRP transporters (Nagy et al., 2009; Panzeri et al., 2011). It remains to be determined if the same cells accumulate Fe and phytate, and if the vacuole is the main site where phytatebound $\mathrm{Fe}$ is localized. Thus, analyses of cellular and subcellular distribution of $\mathrm{Fe}$ and phytate (using phosphorous as a surrogate) will be key for advances in cotyledon biofortification (Punshon et al., 2013). Moreover, understanding how polyphenols affect Fe homeostasis and how their levels could be manipulated will indicate new approaches for seed coat biofortification.

\section{AUTHOR CONTRIBUTIONS}

All authors listed have made a substantial, direct and intellectual contribution to the work, and approved it for publication. common bean (Phaseolus vulgaris L.) and association with newly-mapped candidate genes. Mol. Breed. 30, 1265-1277. doi: 10.1007/s11032-012-9713-Z

Blair, M. W., and Izquierdo, P. (2012). Use of the advanced backcross-QTL method to transfer seed mineral accumulation nutrition traits from wild to Andean cultivated common beans. Theor. Appl. Genet. 125, 1015-1031. doi: 10.1007/s00122-012-1891-x

Blair, M. W., Izquierdo, P., Astudillo, C., and Grusak, M. A. (2013). A legume biofortification quandary: variability and genetic control of seed coat micronutrient accumulation in common beans. Front. Plant Sci. 4:275. doi: $10.3389 /$ fpls.2013.00275

Blair, M. W., Monserrate, F., Beebe, S. E., Restrepo, J., and Flores, J. O. (2010b). Registration of high mineral common bean germplasm lines NUA35 and NUA56 from the red-mottled seed class. J. Plant Regist. 4, 55-59. doi: 10.3198/jpr2008.09.0562 crg

Bouis, H. E. (2007). The potential of genetically modified food crops to improve human nutrition in developing countries. J. Dev. Stud. 43, 79-96. doi: 10.1080/00220380601055585

Bouis, H. E., and Welch, R. M. (2010). Biofortification - a sustainable agricultural strategy for reducing micronutrient malnutrition in the global south. Crop Sci. 50, S20-S32. doi: 10.2135/cropsci2009.09.0531

Broughton, W. J., Hernandez, G., Blair, M. W., Beebe, S. E., Gepts, P., and Vanderleyden, J. (2003). Beans (Phaseolus spp.) - model food legumes. Plant Soil 252, 55-128. doi: 10.1023/A:1024146710611

Brumbarova, T., Bauer, P., and Ivanov, R. (2015). Molecular mechanisms governing Arabidopsis iron uptake. Trends Plant Sci. 20, 124-133. doi: 10.1016/j.tplants.2014.11.004

Campion, B., Glahn, R. P., Tava, A., Perrone, D., Doria, E., Sparvoli, F., et al. (2013). Genetic reduction of antinutrients in common bean (Phaseolus vulgaris L.) seed, increases nutrients and in vitro iron bioavailability without depressing main agronomic traits. Field Crops Res. 141, 27-37. doi: $10.1016 /$ j.fcr.2012.10.015 
Connorton, J. M., Jones, E. R., Rodriguez-Ramiro, I., Fairweather-Tait, S., Uauy, C., and Balk, J. (2017). Vacuolar iron transporter TaVIT2 transports Fe and $\mathrm{Mn}$ and is effective for biofortification. Plant Physiol. 174, 2434-2444. doi: 10.1104/pp.17.00672

Cvitanich, C., Przybylowicz, W. J., Urbanski, D. F., Jurkiewicz, A. M., MesjaszPrzybylowicz, J., Blair, M. W., et al. (2010). Iron and ferritin accumulate in separate cellular locations in Phaseolus seeds. BMC Plant Biol. 10:26. doi: 10.1186/1471-2229-10-26

Dwivedi, S. L., Sahrawat, K. L., Rai, K. N., Blair, M. W., Andersson, M., and Pfieffer, W. (2012). Nutritionally enhanced staple food crops. Plant Breed. Rev. 34, 169-262. doi: 10.1002/9781118358566.ch3

Estrada-Navarrete, G., Alvarado-Affantranger, X., Olivares, J. E., Guillén, G., DíazCamino, C., Campos, F., et al. (2007). Fast, efficient and reproducible genetic transformation of Phaseolus spp. by Agrobacterium rhizogenes. Nat. Protoc. 2, 1819-1824. doi: 10.1038/nprot.2007.259

Finkelstein, J. L., Haas, J. D., and Mehta, S. (2017). Iron-biofortified staple food crops for improving iron status: a review of the current evidence. Curr. Opin. Biotech. 44, 138-145. doi: 10.1016/j.copbio.2017. 01.003

Hindt, M. N., Akmakjian, G. Z., Pivarski, K. L., Punshon, T., Baxter, I., Salt, D. E., et al. (2017). BRUTUS and its paralogs, BTS LIKE1 and BTS LIKE2, encode important negative regulators of the iron deficiency response in Arabidopsis thaliana. Metallomics 9, 876-890. doi: 10.1039/C7MT $00152 \mathrm{E}$

Johnson, A. A., Kyriacou, B., Callahan, D. L., Carruthers, L., Stangoulis, J., Lombi, E., et al. (2011). Constitutive overexpression of the OsNAS gene family reveals single-gene strategies for effective iron- and zinc-biofortification of rice endosperm. PLoS ONE 6:e24476. doi: 10.1371/journal.pone.0024476

Kim, S. A., Punshon, T., Lanzirotti, A., Li, L., Alonso, J. M., Ecker, J. R., et al. (2006). Localization of iron in Arabidopsis seed requires the vacuolar membrane transporter VIT1. Science 314, 1295-1298. doi: 10.1126/science.1132563

Kobayashi, T., Nagasaka, S., Senoura, T., Itai, R. N., Nakanishi, H., and Nishizawa, N. K. (2013). Iron-binding haemerythrin RING ubiquitin ligases regulate plant iron responses and accumulation. Nat. Commun. 4:2792. doi: $10.1038 /$ ncomms3792

Kuo, H. F., Chang, T. Y., Chiang, S. F., Wang, W. D., Charng, Y. Y., and Chiou, T. J. (2014). Arabidopsis inositol pentakisphosphate 2-kinase, AtIPK1, is required for growth and modulates phosphate homeostasis at the transcriptional level. Plant J. 80, 503-515. doi: 10.1111/tpj.12650

Malnoy, M., Viola, R., Jung, M. H., Koo, O. J., Kim, S., Kim, J. S., et al. (2016). DNAfree genetically edited grapevine and apple protoplast using CRISPR/Cas9 ribonucleoproteins. Front. Plant Sci. 7:1904. doi: 10.3389/fpls.2016.01904

Nagy, R., Grob, H., Weder, B., Green, P., Klein, M., Frelet-Barrand, A., et al. (2009). The Arabidopsis ATP-binding cassette protein AtMRP5 / AtABCC5 is a high affinity inositol hexakisphosphate transporter involved in guard cell signaling and phytate storage. J. Biol. Chem. 284, 33614-33622. doi: 10.1074/jbc.M109.030247

Naranjo-Arcos, M. A., Maurer, F., Meiser, J., Pateyron, S., Fink-Straube, C., and Bauer, P. (2017). Dissection of iron signaling and iron accumulation by overexpression of subgroup Ib bHLH039 protein. Sci. Rep. 7:10911. doi: 10.1038/s41598-017-11171-7

Panzeri, D., Cassani, E., Doria, E., Tagliabue, E., Forti, L., Campion, B., et al. (2011). A defective ABC transporter of the MRP family, responsible for the bean lpal mutation, affects the regulation of the phytic acid pathway, reduces seed myo-inositol and alters ABA sensitivity. New Phytol. 191, 70-83. doi: 10.1111/j.1469-8137.2011.03666.x

Petry, N., Boy, E., Wirth, J. P., and Hurrell, R. F. (2015). The potential of the common bean (Phaseolus vulgaris) as a vehicle for iron biofortification. Nutrients 7, 1144-1173. doi: 10.3390/nu7021144

Petry, N., Egli, I., Gahutu, J. B., Tugirimana, P. L., Boy, E., and Hurrell, R. (2012). Stable iron isotope studies in Rwandese women indicate that the common bean has limited potential as a vehicle for iron biofortification. J. Nutr. 142, 492-497. doi: 10.3945/jn.111.149286

Petry, N., Egli, I., Gahutu, J. B., Tugirimana, P. L., Boy, E., and Hurrell, R. (2014). Phytic acid concentration influences iron bioavailability from biofortified beans in Rwandese women with low iron status. J. Nutr. 144, 1681-1687. doi: $10.3945 /$ jn. 114.192989
Petry, N., Rohner, F., Gahutu, J. B., Campion, B., Boy, E., Tugirimana, P. L., et al. (2016). In Rwandese women with low iron status, iron absorption from low-phytic acid beans and biofortified beans is comparable, but low-phytic acid beans cause adverse gastrointestinal symptoms. J. Nutr. 146, 970-975. doi: $10.3945 /$ jn. 115.223693

Pfeiffer, W. H., and McClafferty, B. (2007). HarvestPlus: breeding crops for better nutrition. Crop Sci. 47, S88-S105. doi: 10.2135/cropsci2007.09.0020IPBS

Punshon, T., Ricachenevsky, F. K., Hindt, M. N., Socha, A. L., and Zuber, H. (2013). Methodological approaches for using synchrotron X-ray fluorescence (SXRF) imaging as a tool in ionomics: examples from Arabidopsis thaliana. Metallomics 5, 1133-1145. doi: 10.1039/c3mt00120b

Rech, E. L., Vianna, G. R., and Aragão, F. J. (2008). High-efficiency transformation by biolistics of soybean, common bean and cotton transgenic plants. Nat. Protoc. 3, 410-418. doi: 10.1038/nprot.2008.9

Roschzttardtz, H., Bustos, S., Coronas, M. F., Ibeas, M. A., Grant-Grant, S., and Vargas-Pérez, J. (2017). Increasing provasculature complexity in the Arabidopsis embryo may increase total iron content in seeds: a hypothesis. Front. Plant Sci. 8:960. doi: 10.3389/fpls.2017.00960

Schuler, M., and Bauer, P. (2011). Heavy metals need assistance: the contribution of nicotianamine to metal circulation throughout the plant and the Arabidopsis NAS gene family. Front. Plant Sci. 2:69. doi: 10.3389/fpls.2011.00069

Shi, J., Wang, H., Schellin, K., Li, B., Faller, M., Stoop, J. M., et al. (2007). Embryospecific silencing of a transporter reduces phytic acid content of maize and soybean seeds. Nat. Biotechnol. 25, 930-937. doi: 10.1038/nbt1322

Sperotto, R. A., Ricachenevsky, F. K., Waldow, V. A., and Fett, J. P. (2012). Iron biofortification in rice: it's a long way to the top. Plant Sci. 190, 24-39. doi: 10.1016/j.plantsci.2012.03.004

Stevens, G. A., Finucane, M. M., De-Regil, L. M., Paciorek, C. J., Flaxman, S. R., Branca, F., et al. (2013). Nutrition impact model study G: global, regional, and national trends in haemoglobin concentration and prevalence of total and severe anaemia in children and pregnant and nonpregnant women for 19952011: a systematic analysis of population-representative data. Lancet Glob. Health 1, e16-e25. doi: 10.1016/S2214-109X(13)70001-9

Stevenson-Paulik, J., Bastidas, R. J., Chiou, S. T., Frye, R. A., and York, J. D. (2005). Generation of phytate-free seeds in Arabidopsis through disruption of inositol polyphosphate kinases. Proc. Natl. Acad. Sci. U.S.A. 102, 12612-12617. doi: $10.1073 /$ pnas. 0504172102

Tako, E., Bar, H., and Glahn, R. P. (2016). The combined application of the Caco2 cell bioassay coupled with in vivo (Gallus gallus) feeding trial represents an effective approach to predicting Fe bioavailability in humans. Nutrients 8:732. doi: $10.3390 /$ nu8110732

Vasconcelos, M. W., Gruissem, W., and Bhullar, N. K. (2017). Iron biofortification in the 21st century: setting realistic targets, overcoming obstacles, and new strategies for healthy nutrition. Curr. Opin. Biotechnol. 44, 8-15. doi: 10.1016/j.copbio.2016.10.001

Veltcheva, M., Svetleva, D., Sp, P., and Perl, A. (2005). In vitro regeneration and genetic transformation of common bean (Phaseolus vulgaris L.) problems and progress. Sci. Hortic. 107, 2-10. doi: 10.1016/j.scienta.2005. 07.005

Wang, T. L., Domoney, C., Hedley, C. L., Casey, R., and Grusak, M. A. (2003). Can we improve the nutritional quality of legume seeds? Plant Physiol. 131, 886-891. doi: 10.1104/pp.102.017665

Welch, R. M., House, W. A., Beebe, S., and Cheng, Z. (2000). Genetic selection for enhanced bioavailable levels of iron in bean (Phaseolus vulgaris L.) seeds. J. Agric. Food Chem. 48, 3576-3580. doi: 10.1021/jf0000981

Wirth, J., Poletti, S., Aeschlimann, B., Yakandawala, N., Drosse, B., Osorio, S., et al. (2009). Rice endosperm iron biofortification by targeted and synergistic action of Nicotianamine synthase and ferritin. Plant Biotech. J. 7, 631-644. doi: 10.1111/j.1467-7652.2009.00430.x

Wolt, J. D., Wang, K., and Yang, B. (2016). The regulatory status of genome-edited crops. Plant Biotechnol. J. 14, 510-518. doi: 10.1111/pbi.12444

Xu, X. H., Zhao, H. J., Liu, Q. L., Frank, T., Engel, K. H., An, G. H., et al. (2009). Mutations of the multi-drug resistance-associated protein $\mathrm{ABC}$ transporter gene 5 result in reduction of phytic acid in rice seeds. Theor. Appl. Genet. 119, 75-83. doi: 10.1007/s00122-009-1018-1

Yuan, F. J., Zhu, D. H., Tan, Y. Y., Dong, D. K., Fu, X. J., Zhu, S. L., et al. (2012). Identification and characterization of the soybean IPK1 ortholog of a low phytic 
acid mutant reveals an exon-excluding splice-site mutation. Theor. Appl. Genet. 125, 1413-1423. doi: 10.1007/s00122-012-1922-7

Zhang, Y., Xu, Y. H., Yi, H. Y., and Gong, J. M. (2012). Vacuolar membrane transporters OsVIT1 and OsVIT2 modulate iron translocation between flag leaves and seeds in rice. Plant J. 72, 400-410. doi: 10.1111/j.1365-313X.2012.05088.x

Zheng, L., Cheng, Z., Ai, C., Jiang, X., Bei, X., Zheng, Y., et al. (2010). Nicotianamine, a novel enhancer of rice iron bioavailability to humans. PLoS ONE 5:e10190. doi: 10.1371/journal.pone. 0010190
Conflict of Interest Statement: The authors declare that the research was conducted in the absence of any commercial or financial relationships that could be construed as a potential conflict of interest.

Copyright () 2017 Sperotto and Ricachenevsky. This is an open-access article distributed under the terms of the Creative Commons Attribution License (CC BY). The use, distribution or reproduction in other forums is permitted, provided the original author(s) or licensor are credited and that the original publication in this journal is cited, in accordance with accepted academic practice. No use, distribution or reproduction is permitted which does not comply with these terms. 